\title{
Miniaturization of Circularly Polarized Patch Antenna for RFID Reader Applications
}

\author{
Kawther Mekki \\ Department of Physics \\ University of Tunis El Manar \\ Tunis, Tunisia \\ kawther.mekki@gmail.com \\ Chokri Boussetta \\ Department of Physics \\ University of Tunis El Manar \\ Tunis, Tunisia \\ chokri.boussetta@gmail.com
}

\author{
Omrane Necibi \\ Faculty of Computer and Information Sciences \\ Al Jouf University \\ Jouf, Saudi Arabia \\ oncibi@edu.ju.sa \\ Ali Gharsallah \\ Department of Physics \\ University of Tunis El Manar \\ Tunis, Tunisia \\ ali.gharsallah@fst.utm.tn
}

\begin{abstract}
This paper presents a Circularly Polarized Microstrip Patch Antenna (CPMPA) miniaturization with parasitic elements, suitable for UHF RFID systems. The antenna consists of a half E-shaped patch with cuts. A truncated corner patch can generate an additional Circular Polarization (CP) radiation mode and further enhance the axial ratio. Two symmetric cross shaped slots along the horizontal axis of the CPMPA have been embedded, and its dimension optimization has been based on parametric analysis. Thanks to this slotted structure and reduced surface area, good $\mathrm{CP}$ quality has been obtained with a $25 \%$ overall size reduction. The proposed antenna is lightweight, low profile, simple, and easily produced. The structure's simulation is made using CST Studio Suite 2014 to compute return loss (S11), gain, and the axial ratio of the antenna while the overall miniaturized antenna's volume is $77 \mathrm{~mm} \times 58 \mathrm{~mm} \times 1.6 \mathrm{~mm}$ operating at $915 \mathrm{MHz}$.
\end{abstract}

\section{Keywords-RFID; return loss; axial ratio; slots; gain}

\section{INTRODUCTION}

Radio Frequency Identification (RFID) is widely used in many applications. UHF RFID must provide appropriate isolation for high reader sensitivity, which is a key to an extended reading range of the RFID reader. Many applications require compact CPMAs, where the overall size of the antenna is an important factor [1]. For RFID systems, the size of the antenna is very important, especially for low frequency bands, and so is its gain. Moreover, the antenna must cover the desired frequency bands for intended wireless applications, such as ultra-high frequency (UHF) RFID for implanted antennas and circularly polarized patch antennas for RFID reader applications [2]. Several antennas have been designed the last few years for RFID readers, such as the helical antenna [3], the loop antenna [4], the PIFA antenna [5], the unipolar antenna [6], the Yagi antenna printed with three elements [7], etc. The proposed antenna is designed to enable faster and more accurate communication of EPC-compliant passive tag data to
RFID readers, even in harsh RF environments. The aim is to achieve higher performance, due to its low reflection coefficient, good gain, inherent power, and circular polarization, while maintaining a simple architecture that would make the RFID reader suitable for bi-static operation. Although this structure has simplicity as its main advantage, the drawbacks that might make its use not so favourable are its limitations, notably lesser gain, low bandwidth, and low efficiency [8]. Many studies have been conducted in order to reduce these disadvantages by making a different approach regarding the MPA's geometry, such as the use of slots and splits, like the E-shaped [9], U-shaped [10], L-shaped [11] structures. This led to the improvement of performance to a certain level that made them widely used in wireless applications such as military devices, GPS, satellite communications, RFID, etc.

In this work, a modified CPMPA is presented, designed on an FR4 substrate for an RFID reader. The modifications made on this structure are mainly two symmetrical cross slots that contribute to its miniaturization, and the improvement of its reflection coefficient.

\section{CPMPA STRUCTURE AND DESIGN}

\section{A. Design}

The circular polarization can reduce the transmission loss affected by misalignment between two connected antennas and offers better system performance and better mobility compared to linear polarization. Two sided corner truncation technique was implemented on both sides of the patch so that better impedance matching across the operating bands can be obtained [12-14]. Corner truncation also ensures the circular polarization of the antenna. Figure 1 shows a basic rectangular CPMPA, with truncated edge technique applied on its edges. The proposed antenna component has an antenna patch, placed on a FR4 substrate with dielectric constant $\left(\varepsilon_{\mathrm{r}}\right)$ of 4.7 and 
thickness (h) of 1.6mm. PEC material was used for ground and patch with standard thickness of $0.035 \mathrm{~mm}$. The MPA dimensions at the $915 \mathrm{MHz}$ frequency are listed in Table I.

Lg

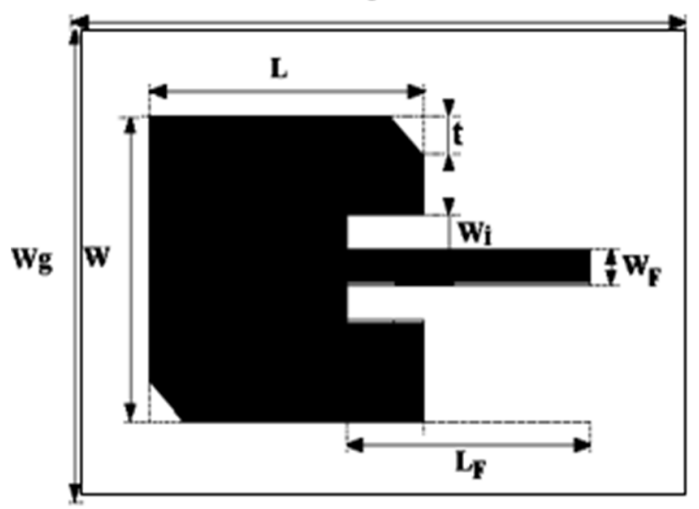

Fig. 1. Proposed Circularly Polarized Microstrip Patch Antenna (CPMPA)

TABLE I. MICROSTRIP ANTENNA DIMENSIONS

\begin{tabular}{|c|c|}
\hline Parameters & Values (mm) \\
\hline $\mathrm{W}$ & 98 \\
\hline $\mathrm{L}$ & 76 \\
\hline $\mathrm{Wg}$ & 107 \\
\hline $\mathrm{Lg}$ & 87 \\
\hline $\mathrm{t}$ & 10 \\
\hline $\mathrm{Wg}$ & 2 \\
\hline
\end{tabular}

The microstrip antenna dimensions are based on standard mathematical models inspired by the literature for the design of the MPA [15-16]. In order to analyze the performance of the antenna, certain parameters need to be taken into account, such as the return loss S11, gain, and directivity. The antenna's response is tuned by adjusting the substrate width $(\mathrm{Wg})$, substrate length ( $\mathrm{Lg})$, antenna width (W), antenna length (L), antenna feed length (Lg), antenna feed width (Wf), choosing substrate material, thickness and size of the truncated segment (t1 and $\mathrm{t} 2$ ).

\section{B. Results and Discussion}

The CPMPA has a return loss value of $-17 \mathrm{~dB}$ at its resonance frequency of $915 \mathrm{MHz}$ (Figure 2). The CPMPA's resonant frequency is not the desired frequency but the structure overall radiates with a circular polarization. Modifying the truncated segments ( $\mathrm{t} 1$ and $\mathrm{t} 2$ ) results in maintaining the desired polarization while shifting the resonant frequency. These segments dimensions are chosen depending on obtaining desired results while maintaining satisfying matching and low VSWR. The radiation property of most concern is the two or three-dimensional spatial distribution of radiated energy as a function of the observer's position along a path or surface of constant radius. The simulated gain of the CPMPA structure is shown in Figure 3. The simulated gain of the antenna in the normal direction to the patch is equal to $5.1 \mathrm{~dB}$ at $915 \mathrm{MHz}$. The simulated axial bandwidths at $915 \mathrm{MHz}$ is less than $-3 \mathrm{~dB}$. Figure 4 shows the simulated axial ratio of the antenna without the connected patch.

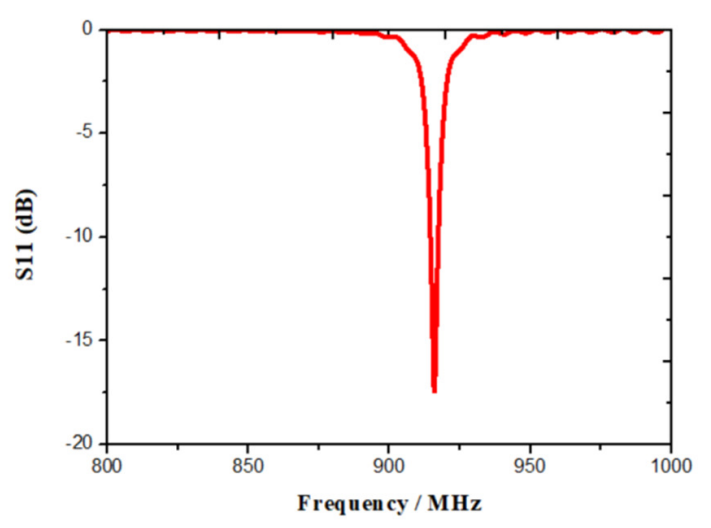

Fig. 2. Simulated return loss S11 of CPMPA

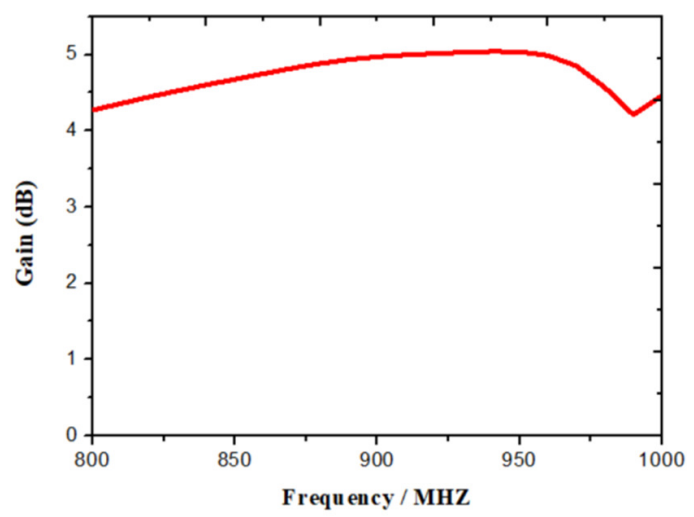

Fig. 3. Gain of simulated CPMPA

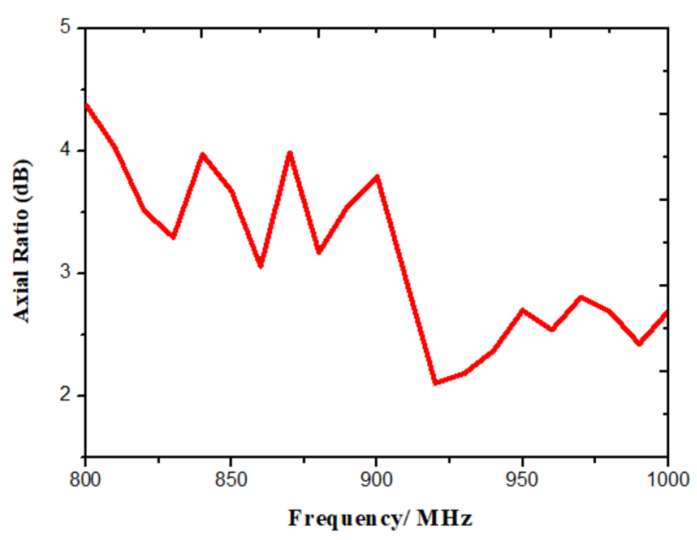

Fig. 4. Simulated axial ratio

\section{A MINIATURIZED CPMPA}

There are many miniaturization concepts that are intended to artificially lengthen the dimensions of the resonant device. Among these techniques, we find the electrical elongation of the path of the current by modifying the antenna structure, the addition of parasitic elements or the use of particular materials. In this paper we will discuss the first technique of modifying the geometry of the radiating element by inserting slots on the patch. This technique of miniaturization is the most widespread 
today and concerns a panel of antennal forms. On the radiating elements, such as patch antennas, the use of slots in a radiating element allows, when properly positioned, increasing the distance traveled by the surface current. Indeed, a current flowing from one end to the other of the metal part of the antenna will be blocked by the slots. To get around them, it will have to take a longer path than the one without the slots. The length traveled by the current is greater, the wavelength of the antenna is artificially elongated, and its operating frequency is lower. With this technique it is possible to reduce the size of an antenna up to $25 \%$. However, the quality factor increases with the number of slots, which has the effect of degrading the bandwidth. Depending on their shape and location, the slots may optionally introduce capacitive and inductive effects. If these effects are properly controlled, they can increase the bandwidth of the antenna.

But before discussing this technique, it is necessary to see the distribution of the surface current on the antenna structure in order to find the hot zones of the structure where a great concentration of surface current occurs. The slots must be placed according to these positions. The current distribution on the patch allows finding the ideal location for creating slots, for the structure to be optimized. This distribution is shown in Figure 5.

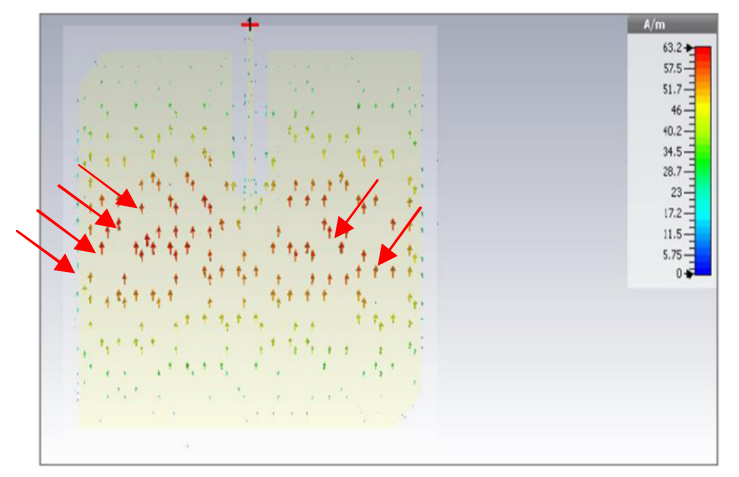

Fig. 5. Surface current distribution at $915 \mathrm{MHz}$

A concentration of surface current on both sides of the excitation line is noticed, so slots will be inserted in the middle of the structure in a symmetrical way.

\section{A. Parametric Study of Cross Slot CPMPA}

This work is directed to having a miniaturized antenna for the RFID reader. The modifications consist of creating two symmetric cross slots then change the dimensions of the CPMPA to meet miniaturization. The miniaturization process of the antenna is based on a parametric study, by using the parameter scanning function provided by CST. In order to highlight the effect of modifying certain parameters of the antenna on its response, only one parameter is modified at a time, while the others (the structure's dimensions) remain constant. The structure shown in Figure 6 is the geometry of a miniaturized microstrip patch antenna, created with the two engraved symmetric slots technique.

As with every design of a new structure, optimization is always important for better performance. Indeed, the parametric study allows us to define the effect of each parameter on the overall characteristics of the antenna. The method to achieve our goal is to embed symmetric slots on the CPMPA and reduce the size of the patch to get the desired resonance frequency by controlling the return loss parameters. By using the same dimensions, truncating the edges of the MPA causes a shifting in the resonant frequency from $894 \mathrm{MHz}$ (Figure 7-1) up to $915 \mathrm{MHz}$ (Figure 7-2), while changing the polarization to circular, and with the integration of slots, the resonance frequency decreases to around $840 \mathrm{MHz}$ (Figure 7$3)$.

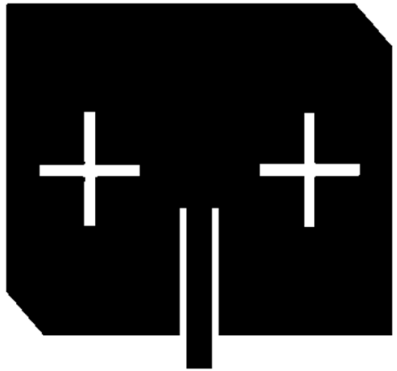

(a)

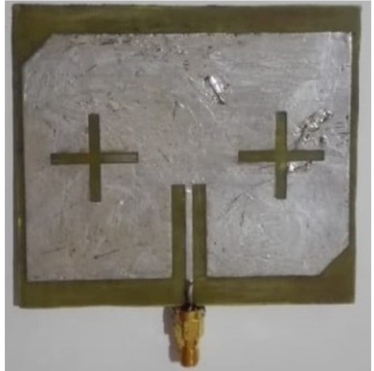

(b)
Fig. 6. Geometry of the proposed two symmetrical cross-shaped slots CPMPA: (a) simulated structure, (b) fabricated structure, where $\mathrm{W}=77, \mathrm{~L}=58$, $\mathrm{Wg}=80, \mathrm{Lg}=67, \mathrm{Ws}=1.5, \mathrm{Ls}=12$ (all dimensions in $\mathrm{mm})$

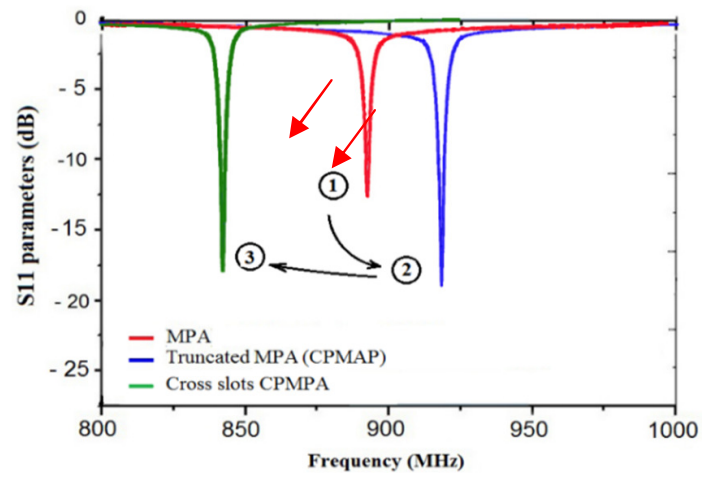

Fig. 7. The simulated return loss of a cross slotted CPMPA based on two symmetric slots

\section{B. The Effects of Cross Shape Slot Length Ls and Width Ws Variation}

The return loss is greatly influenced by the length Ls of the cross shape slot, as depicted in Figure 8(a). The increase of this parameter from $11 \mathrm{~mm}$ to $13 \mathrm{~mm}$ leads to a decrease of the resonance frequency. The path of surface current on the patch is extended by the cross shape slot. As a result the operating frequency drops and thus the antenna size can be reduced. Similarly, the return loss is influenced by the width Ws of the cross shape slot, as shown in Figure 8(b). The increase in Ws from $1 \mathrm{~mm}$ to $2 \mathrm{~mm}$ leads to a slight decrease in the resonant frequency shifts compared to Ls variations, while keeping the impedance and AR bandwidths hardly influenced. As before, the path of surface current on the patch is extended by the cross shape slot. As a result, the operating frequency decreases and thus size reduction can be obtained. 
(a)

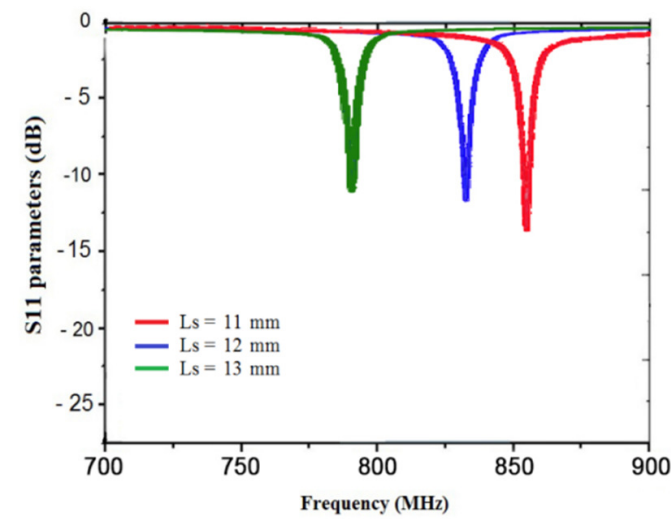

(b)

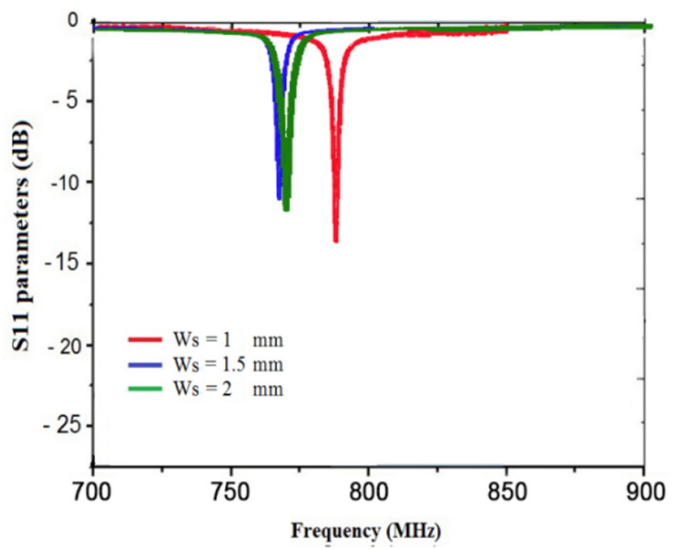

Fig. 8. Reflection coefficient for different values of (a) Ls and (b) Ws

We can conclude from Figure 8 that both Ls and Ws affect the operating frequency, with Ls having most significant effects. The length Ls of the cross shape slot has been parametrically studied in the range of $[8 \mathrm{~mm}(\lambda / 40)-16 \mathrm{~mm}$ $(\lambda / 20)]$, from which $12 \mathrm{~mm}(\lambda / 25)$ gave the most satisfying result. So, $12 \mathrm{~mm}$ and $1.5 \mathrm{~mm}$ for Ls and $\mathrm{Ws}$ respectively are selected as the optimal values at $915 \mathrm{MHz}$.

\section{Results and Discussion}

The simulated and measured performance of the proposed cross slot CPMPA was compared with some related published compact CPMA structures [17]. The comparison between simulated and measured return loss values is shown in Figure 9. We can see that the simulated and measured results are in a good agreement. The comparison between simulation results and those of [17] allows us to conclude that they are in agreement, with slight difference in resonance frequency $(5 \mathrm{MHz})$. In fact, the simulated bandwidth ranges from $892 \mathrm{MHz}-940 \mathrm{MHz}(48 \mathrm{MHz})$ while the bandwidth found in [17] ranges from $886 \mathrm{MHz}$ to $930 \mathrm{MHz}(44 \mathrm{MHz})$. The two simulated resonance frequencies of the proposed antenna and the one in [17] are $915 \mathrm{MHz}$ and $910 \mathrm{MHz}$ respectively. The simulated resonance frequency and measured resonance frequency of the proposed antenna are $915 \mathrm{MHz}$ and $913 \mathrm{MHz}$ respectively. The simulated and measured $-10 \mathrm{~dB}$ return-loss bandwidths of this antenna are $48 \mathrm{MHz}(893 \mathrm{MHz}-940 \mathrm{MHz})$ and $30 \mathrm{MHz}(900 \mathrm{MHz}-930 \mathrm{MHz})$ respectively. Moreover, the desired operating frequencies slightly shift from $915 \mathrm{MHz}$ (simulation) to $913 \mathrm{MHz}$ (measured) with return-loss values shifting as well, from $-40 \mathrm{~dB}$ (simulation) to $-35 \mathrm{~dB}$ (measured). It can be concluded that the simulation results are in good agreement with the actual measurements. The small difference between the simulated and measured results may be due to the effect of SMA connector soldering and tolerance levels during the fabrication process. Overall, the extracted results from the studied structure are considered better than those of the structures proposed in [17]. This difference in simulated results can be caused by the use of the slots and the type of the chosen excitation. The presence of a single resonance is remitted for the CST simulation while for the measurements the presence of two adjective resonances is distinguished. This difference is essentially due to the choosing of the Ws and Ls parameters, because the return loss parameter S11 and the bandwidth are very sensitive to their variations. The fact of inserting two symmetric slots on the circular polarization microstrip antenna allows maintaining gain while ensuring a good matching at $915 \mathrm{MHz}$.

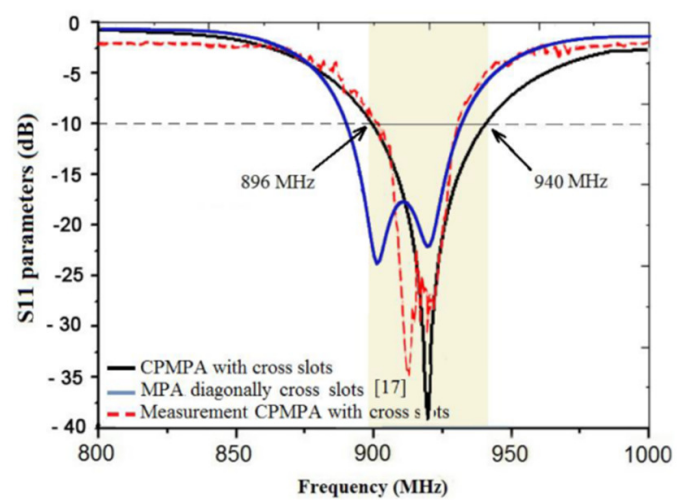

Fig. 9. Reflection coefficient S11 of the miniaturized antenna

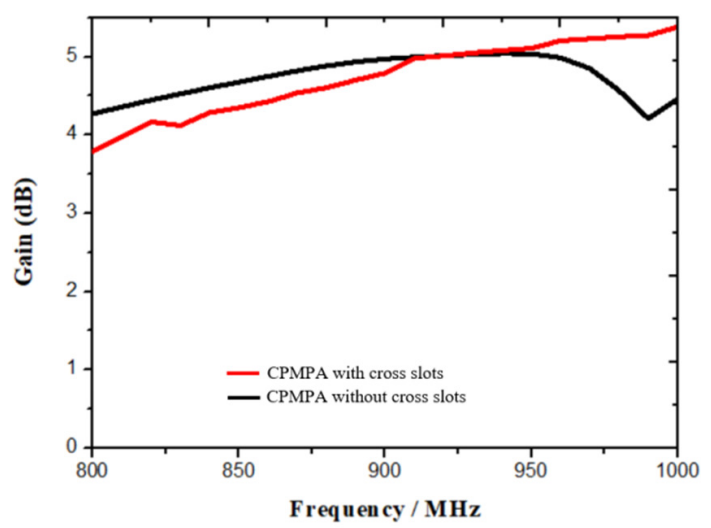

Fig. 10. Gain of the CPMPA with and without cross slots

\section{Structure Comparison}

Overall, the obtained results are found to be better than those of the structures proposed in [17-20]. Table II shows a comparison between the proposed antenna and the structures mentioned previously showing a better bandwidth in terms of both return loss and gain. When it comes to miniaturization, surface reduction size of $40 \%$ is achieved and an overall size reduction of $25 \%$ compared to the basic MPA is obtained. 
TABLE II. COMPARISON OF CP MICROSTRIP ANTENNA

\begin{tabular}{|c|c|c|c|c|c|}
\hline Antenna & Description & $\begin{array}{c}\text { Return loss at } F_{R} \\
\text { (dB) }\end{array}$ & $\begin{array}{c}\text { Operating frequency } \mathrm{F}_{\mathrm{R}} \text { of } \mathrm{CP} \\
(\mathrm{MHz})\end{array}$ & $\begin{array}{c}\text { Overall antenna size } \\
\left(\mathrm{mm}^{2}\right)\end{array}$ & $\begin{array}{l}\text { Gain } \\
\text { (dB) }\end{array}$ \\
\hline$[17]$ & Slotted CPMA for RFID & -24 & 910 & $80 \times 80$ & 3.07 \\
\hline [18] & Asymmetrical circular slotted & -38 & 900 & $90 \times 90$ & 3.7 \\
\hline [19] & CP cross shaped slotted & -24 & 910 & $90 \times 90$ & 3.8 \\
\hline$[20]$ & Compact CPMA for RFID & -20 & 920 & $90 \times 90$ & 3.4 \\
\hline Proposed & CP cross shape symmetric slot & -40 & 915 & $77 \times 58$ & 5.09 \\
\hline
\end{tabular}

\section{CONCLUSION}

A compact circularly polarized symmetric cross slotted MPA has been studied, simulated, and manufactured. The prototype made has a reduced size and delivers an exceptional performance with enhanced return loss value of $-40 \mathrm{~dB}$ and an unusual high gain peaking up to $5.09 \mathrm{dBi}$. In addition, usability of the reader unit in terms of reading directions and orientations of tags was ensured by the gain of $5.09 \mathrm{dBi}$ while the beamwidth value was $103^{\circ}$. The small sized proposed antenna design can be easily manufactured for UHF RFID reader applications.

\section{ACKNOWLEDGMENT}

The authors wish to thank the Laboratory for Research on Microwave Electronics Department of Physics, FST Tunis University Tunis El Manar Tunis, Tunisia.

\section{REFERENCES}

[1] A. Trevarthen, "The national livestock identification system: The importance of traceability in e-business", Journal of Theoretical and Applied Electronic Commerce Research, Vol. 2, No. 1, pp. 49-62, 2007

[2] J. Li, H. Liu, S. Zhang, M. Luo, Y. Zhang, S. He, “A wideband singlefed, circularly-polarized patch antenna with enhanced axial ratio bandwidth for UHF RFID reader applications”, IEEE Access, Vol. 6, pp. 55883-55892, 2018

[3] S. H. Z. Deen, H. A. Malhat, K. H. Awadalla, "Octafilar helical antenna for handheld UHF RFID reader", 28th National Radio Science Conference, Cairo, Egypt, April 26-28, 2011

[4] K. D'hoe, N. Stevens, J. P. Goemaere, L. D. Strycker, B. Nauwelaers, "Optimization of an RFID loop antenna with smart goal functions", IEEE International Conference on RFID-Technologies and Applications, Nice, France, November 5-7, 2012

[5] S. Islam, K. P. Esselle, L. Matekovits, D. Bull, P. M. Pilowsky, "An implantable PIFA antenna with a J-shaped proximity feed for RFID telemetry", 21st International Conference on Applied Electromagnetics and Communications, Dubrovnik, Croatia, October 14-16, 2013

[6] P. T. Selvan, S. Raghavan, "Neural network model for design of compact CPW-fed monopole antenna for $5.8 \mathrm{GHz}$ RFID application", 2nd International Conference on Computing, Communication and Networking Technologies, Karur, India, July 29-31, 2010

[7] H. X. D. Araujo, S. E. Barbin, L. C. Kretly, "Design of an UHF QuasiYagi antenna with metamaterial structures for RFID application", SBMO/IEEE MTT-S International Microwave and Optoelectronics Conference, Natal, Brazil, October 29-November 1, 2011

[8] V. Nagaraju, P. V. Madhav, V. M. Kumar, "Optimization of patch size of fractal hybrid antenna for GPS application", International Journal of Engineering Research and Applications, Vol. 3, No. 1, pp. 2003-2008, 2013

[9] A. Khidre, K. F. Lee, F. Yang, A. Z. Elsherbeni, "Circular polarization reconfigurable wideband E-shaped patch antenna for wireless applications", IEEE Transactions on Antennas and Propagation, Vol. 61, No. 2, pp. 960-964, 2013
[10] V. K. Singh, Z. Ali, "Dual band U-shaped microstrip antenna for wireless communication", International Journal of Engineering Science and Technology, Vol. 2, No. 6, pp. 1623-1628, 2010

[11] M. H. Ullah, M. T. Islam, J. S. Mandeep, N. Misran, "A new double Lshaped multiband patch antenna on a polymer resin material substrate", Applied Physics A, Vol. 110, No. 1, pp. 199-205, 2013

[12] N. Jain, A. Khare, R. Nema, "E-shape micro strip patch antenna on different thickness for pervasive wireless communication", International Journal of Advanced Computer Science and Applications, Vol. 2, No. 4, pp. 117-123, 2011

[13] C. Deng, X. Lv, Z. Feng, "Low-profile circularly polarised patch-ring antenna with compact feeding network", IET Microwaves Antennas \& Propagation, Vol. 12, No. 3, pp. 410-415, 2017

[14] R. Swetha, L. Anjaneyulu, "Compact circularly polarized patch antenna for WiMAX applications with improved impedance bandwidth and axial ratio", Engineering, Technology \& Applied Science Research, Vol. 10, No. 1, pp. 5104-5107, 2020

[15] M. M. Nahas, M. Nahas, "Bandwidth and efficiency enhancement of rectangular patch antenna for SHF applications", Engineering, Technology \& Applied Science Research, Vol. 9, No. 6, pp. 4962-4967, 2019

[16] J. Elluru, S Varadarajan, "Design of UHF-band microstrip patch antenna for wind profiler radar", International Journal of Advance Engineering and Research Development, Vol. 4, No. 8, pp. 567-572, 2017

[17] S. Kumar, R. K. Vishwakarma, R. Kumar, J. Anguera, A. Andujar, "Slotted circularly polarized microstrip antenna for RFID application", Radioengineering, Vol. 26, No. 4, pp. 1025-1032, 2017

[18] Nasimuddin, Z. N. Chen, X. Qing, “Asymmetrical-circular shaped slotted microstrip antennas for circular polarization and RFID applications", IEEE Transactions on Antennas and Propagation, Vol. 58, No. 12 , pp. 3821-3828, 2010

[19] Nasimuddin, Z. N. Chen, X. Qing, "A compact circularly polarized cross-shaped slotted microstrip antenna", IEEE Transactions on Antennas and Propagation, Vol. 60, No. 3, pp. 1584-1588, 2012

[20] Nasimuddin, X. Qing, Z. N. Chen, "Compact circularly polarized microstrip antenna for RFID handheld reader applications", Asia Pacific Microwave Conference, Singapore, Singapore, December 7-10, 2009 